\title{
Disrupción endocrina en obesidad y diabetes
}

$\mathrm{U}$ n gran número de productos químicos fabricados por el hombre y utilizados en la industria, así como algunos otros productos naturales, tienen el potencial de alterar el sistema endocrino de los animales, incluyendo al hombre.

En un editorial previo, el Dr. Enrique Ardila había comentado las generalidades sobre la disrupción endocrina (1); sin embargo, en esta ocasión comento lo relacionado con la disrupción endocrina en la obesidad y en la diabetes mellitus 1 y 2. En el presente número se publica una amplia revisión de las sustancias químicas presentes en los agentes industriales, farmacéuticos, agropecuarios, plásticos, preservantes y pesticidas que actúan como disruptores endocrinos, ya que alteran el metabolismo de los hidratos de carbono y favorecen el desarrollo de estas enfermedades (2). Los llamados obesógeos (ftalatos y parabenos) aumentan el número y el tamaño de los adipocitos por la interferencia con los reguladores transcripcionales del tipo PPAR (peroxisome proliferator-activated receptor), que favorecen la diferenciación de preadipocitos a adipocitos (3).

Otros, como los fitoestrógenos (genisteína y daidzeína), interfieren sobre los receptores esteroideos, alterando el almacenamiento lipídico no solo en el individuo, sino que al ser utilizados durante la gestación y lactancia contribuyen a la obesidad en la descendencia. Los productos perfluoroalquilados aumentan la adiposidad y reducen la sensibilidad a la insulina; el bisfenol A (BPA) puede alterar la sensación hambre/ saciedad moviendo el balance energético a favor del almacenamiento calórico.

Otro mecanismo postulado para esta asociación es la capacidad del BPA para inhibir la liberación de adiponectina por parte de los adipocitos; también se ha demostrado que incrementa el contenido de insulina en la célula $\beta$ pancreática (4).
En el caso de la diabetes tipo 1, la presencia de polutos, como el BPA y el ácido perfluoro-undecanoico, puede producir insulitis, así como también la exposición al arsénico, la dioxina, los ftalatos y los bifenilos in utero se asocia con los cambios inmunológicos y la pérdida de la masa de células $\beta$, favoreciendo la presencia de diabetes tipo 1 .

Varios estudios transversales y revisiones de la literatura asocian los niveles de disrupción endocrina con la obesidad, la diabetes tipo 2 y las enfermedades cardiovasculares en humanos. Los disruptores endocrinos que más frecuentemente se asocian con estas enfermedades son aquellos altamente resistentes a la degradación debido a su naturaleza lipofílica, conocidos como polutantes orgánicos persistentes (POP), de los cuales los más comunes son las dioxinas, el BPA, los pesticidas organoclorados, los policlorobifenilos (PCB) y el dicloro difenil tricloroetano (DDT) (diclorodifenildicloroetileno [DDE], principal producto de degradación del DDT). La diabetes tipo 2 y la obesidad tienen mecanismos interrelacionados y superpuestos, como un aumento de la lipólisis, una disminución de la oxidación de glucosa e hiperinsulinemia, todas características de resistencia a la insulina (5).

Por esta razón, es de gran importancia ampliar el conocimiento sobre la relación de todos estos polulantes ambientales para disminuir la exposición a ellos, especialmente en la etapa prenatal, ya que cada vez es más evidente su papel en el favorecimiento de enfermedades tan prevalentes como la obesidad y la diabetes mellitus.

Amanda Páez Talero Médica endocrinóloga. Expresidente de la Asociación Colombiana de Endocrinología, Diabetes y Metabolismo.

\section{Referencias}

1. Ardila E. Editorial: Los disruptores y la endocrinología Rev. Col. Endo. 2018;5(4):4.

2. Sánchez P, Zanabria M, Calvache J, Coy A, Rojas W. Disruptores endocrinos y su camino hacia el desequilibrio metabólico. Rev. Col. Endo. 2020. [Artículo publicado en este número de la revista].

3. Li X, Ycaza J, Blumberg B. The environmental obesogen tributyltin chloride acts via peroxisome proliferator activated receptor gamma to induce adipogenesis in murine 3T3-L1 preadipocytes. J Steroid Biochem Mol Biol. 2011 Oct;127(1-2):9-15.
4. Pérez M, Páez A. Disruptores endocrinos. En: Jacome A, Ardila E, Casas L. A. (eds). Fisiología Endocrina. Bogotá: Manual Moderno. Asociación Colombiana de Endocrinología, Diabetes y Metabolismo; 2017. p. 396-409.

5. Alonso-Magdalena P, Quesada I, Nadal A. Endocrine disruptors in the etiology of type 2 diabetes mellitus. Nat Rev Endocrinol. 2011 Jun;7(6):346-53. 